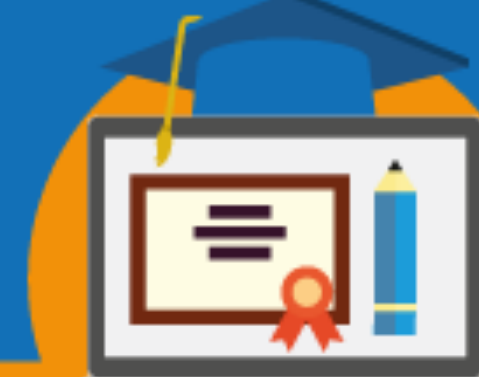

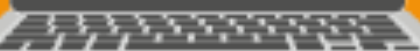

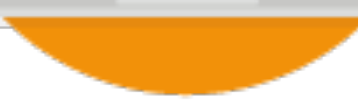

\section{MARCOS REGULATÓRIOS DA EAD (2016-2017): QUALIDADE E INOVAÇÃO DA EDUCAÇÃO EM QUESTÃO}

\author{
Andréia Mello Lacé \\ (UnB/amlace@unb.br) \\ Érika Japiassu Albuquerque \\ (UnB/erikaalbuquerquee@gmail.com) \\ Laryssa Rosa da Silva Slavov \\ (UnB/ laryssaslavov@gmail.com) \\ Wilmar Martins \\ (UnB/wilmarfreitasmartins@gmail.com)
}

Eixo 1: Política, Gestão e financiamento da EaD

\begin{abstract}
Resumo: Este trabalho intenciona apresentar resultados prévios da pesquisa "Política de expansão da educação a distância na UnB: qualidade e inovação em questão" vinculada ao Programa Institucional de Iniciação Científica (PIBIC). O referido estudo é parte integrante do grupo de pesquisa da região Centro-Oeste que agrega pesquisadores de diferentes instituições da região. Sendo assim, o estudo do PIBIC concentrou-se na seguinte questão: quais as concepções de qualidade e inovação estão presentes na oferta e expansão da educação a distância na UnB? Em decorrência do problema de pesquisa, um dos objetivos específicos foi analisar, por meio de abordagem qualitativa, as concepções de qualidade e inovação da educação expressas nas regulamentações da EaD no Brasil (2016-2017). Os estudos de Lima (2014, 2018), Alonso (2009), Dourado (2011) e Lacé (2014) conduziram as análises dos dados, cujos resultados evidenciaram que, a atualização dos marcos legais para a $\mathrm{EaD}$, se vinculam a uma concepção de qualidade utilitária e voltada para a autorregulação do mercado e para a competitividade.
\end{abstract}

Palavras-chave: Qualidade. Inovação. Marco regulatório para a EaD

\section{Introdução}




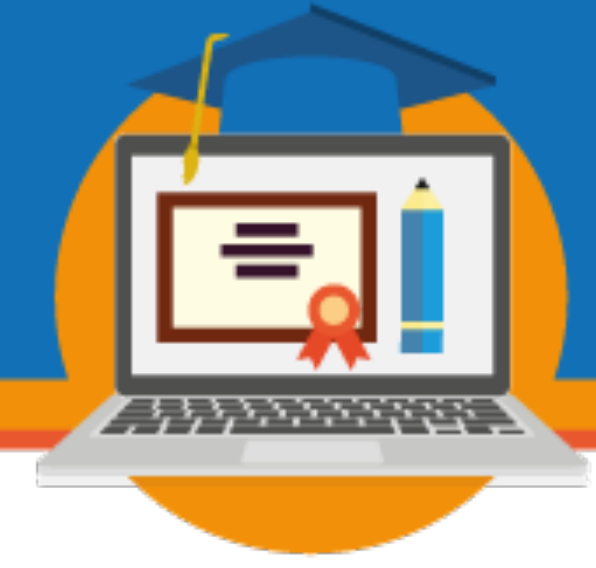

As políticas de Educação Superior no Brasil, a partir de 2002, foram pautadas pelo debate da democratização do acesso, incluindo o uso da modalidade a distância, como estratégia para se alcançar um maior número de pessoas em um país de dimensões continentais como o Brasil. Tais aspectos podem ser observados de forma explícita em documentos como o Plano Nacional de Educação (2001-2010), o Sistema Universidade Aberta do Brasil (Decreto 5.800 de 2006) e o Plano Desenvolvimento da Educação (PDE/2007) (LACÉ, 2014). De acordo com Lima (2018), em relação às matrículas na educação superior a distância por categoria administrativa e por tipo de instituição, tem-se o cenário abaixo.

Gráfico 1 - Matrículas na modalidade a distância por categoria administrativa

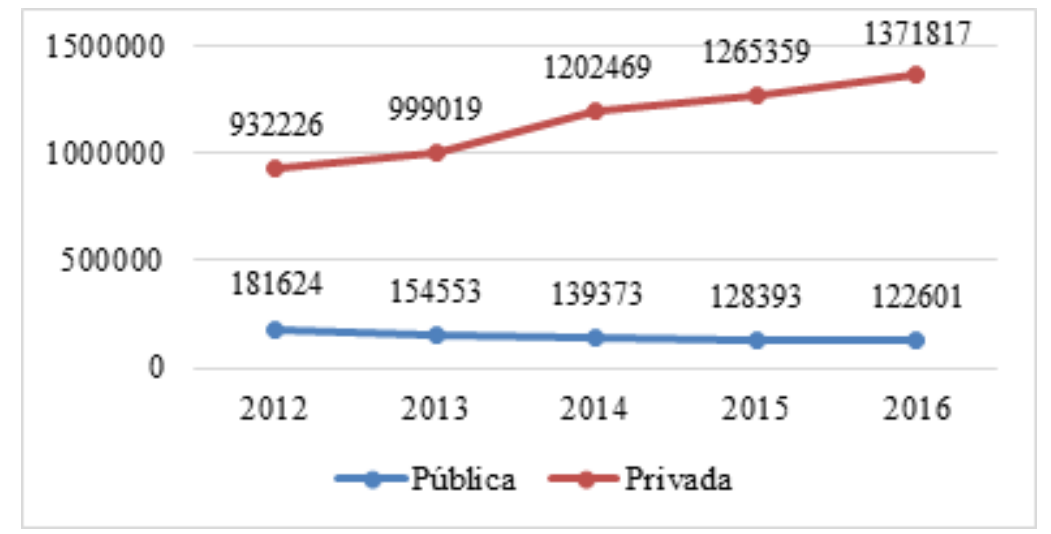

Fonte: Lima (2018, p.33)

Gráfico 2 - Matrículas na modalidade a distância por tipo de instituição de ensino 


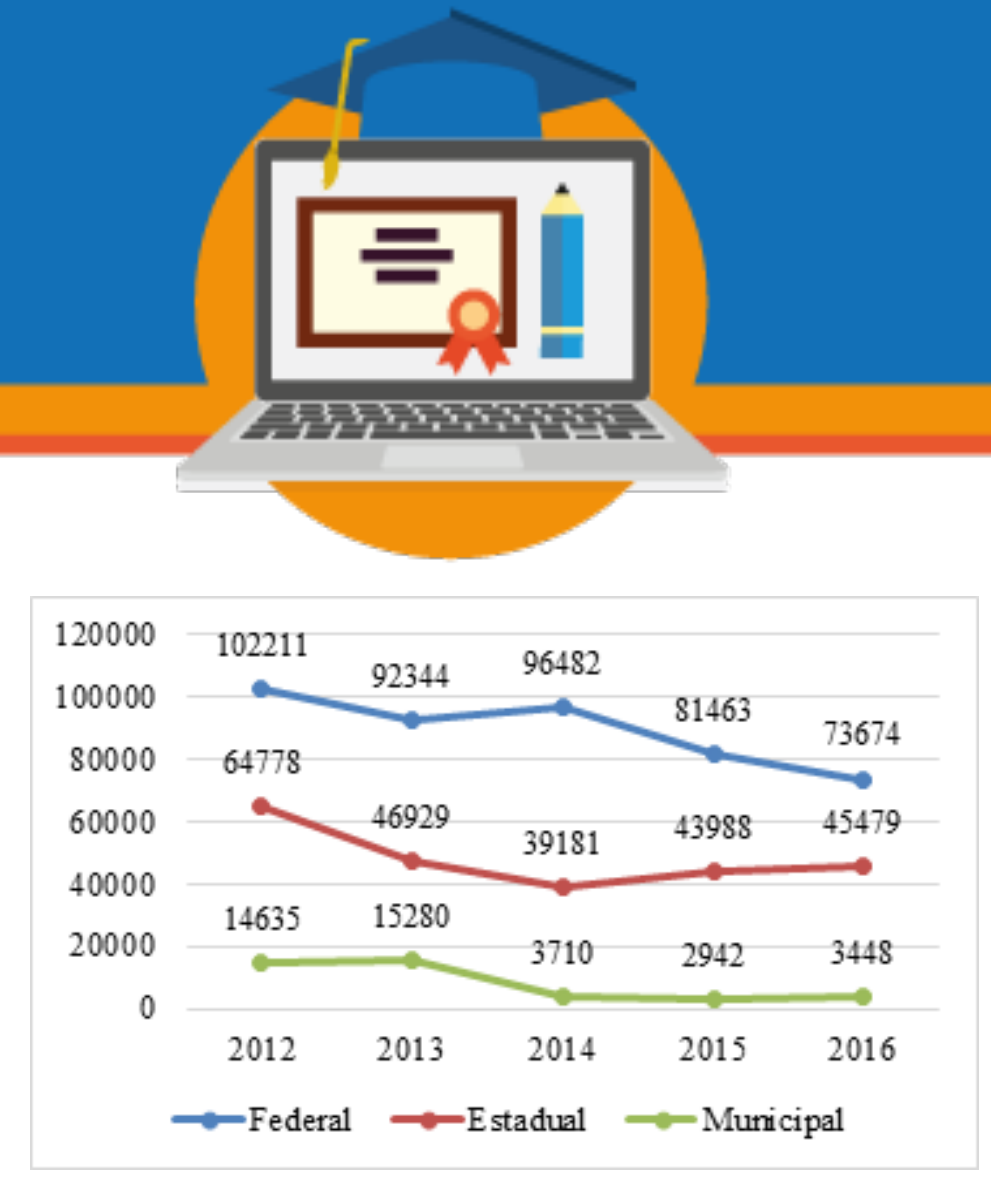

Fonte: Lima (2018, p. 34)

Os gráficos evidenciam de um lado a evolução das matrículas nos cursos de EaD em instituições privadas (com variação de 48,2\% de 2016 em relação a 2012); de outro, queda acentuada nas matrículas nas instituições públicas na série histórica em estudo (com variação de $-32,5 \%$ de 2016 em relação a 2012). A queda acentuada nas instituições públicas se dá pela redução drástica no número de matrículas nas instituições federais de ensino superior (IFES), com índice de $-27,9 \%$ de 2016 em relação a 2012, demonstrando a fragilidade da oferta pelas IFES quando não possuem edital de fomento externo, ou seja, pela falta de editais que ocorreu da UAB entre 2014 e 2018, justamente o período da queda. Situação contextual que também atingiu a Universidade de Brasília. Sendo assim, justifica-se a relevância de se analisar a política de expansão da educação superior a distância na UnB desvelando conceitos como qualidade e inovação, inclusive, nos marcos regulatórios nacionais.

Cabe salientar que o conceito qualidade é polissêmico e dependendo da abordagem e concepção de educação, pode-se transpor para o campo, concepções e insumos típicos das relações mercantis para aferir, quantificar e definir qualidade dos processos educativos. Abadia (2009), analisa algumas dessas transposições e repercussões no campo educacional e evidencia como as políticas educacionais focadas em avaliações estandardizadas e em resultados numéricos materializam essa abordagem mercantil. Desse modo, tal como a autora supracitada, compreendemos o conceito de qualidade em uma perspectiva social "em que a concepção de mundo, de sociedade e de educação evidencia e define os elementos para qualificar, avaliar e

\section{SEMINÁRIO DE EDUCAÇÃO A DISTÂNCIA}

Diálogos sobre EaD e uso das TDIC na educação: regulamentação em tempos recentes 3 a 6 de novembro de 2020 - Brasília/DF - Online 


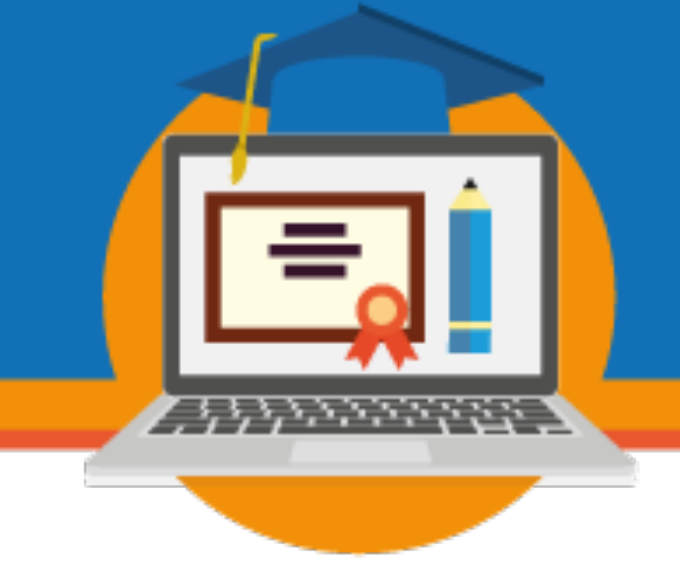

precisar a natureza, as propriedades e os atributos desejáveis de um processo educativo de qualidade social" (DOURADO; OLIVEIRA, 2009, p. 202).

De outro modo, a qualidade social da educação envolve dimensões intra e extraeducacionais, ou seja, devem considerar os diferentes atores, a dinâmica pedagógica (condições de oferta; gestão e organização; formação e ação pedagógica; acesso, permanência e desempenho dos estudantes), bem como os diferentes fatores extraeducacionais (espaço social e obrigações do Estado) que interferem direta ou indiretamente nos resultados (DOURADO; OLIVEIRA, 2009).

Nas palavras de Abadia (2009, p. 225),

[...] a qualidade social da educação escolar não se ajusta, portanto, aos limites, tabelas, estatísticas e fórmulas numéricas que possam medir resultado de processos tão complexos e subjetivos, como advogam alguns setores empresariais [...]. A educação de qualidade (destaque nossos) é aquela que atenta para um conjunto de dimensões socioeconômicas e culturais que circundam o modo de viver e as expectativas das famílias e de estudantes em relação à educação; que busca compreender as políticas governamentais, os projetos sociais [...] voltados para o bem comum" [...].

Assim como o conceito de qualidade, o conceito de inovação também é polissêmico e na maioria dos casos é visto em relação às mudanças políticas, sociais e econômicas que ocorrem nas sociedades. Para Oliveira; Courela (2013), inovação é um processo multidimensional capaz de transformar o espaço onde ocorre; utiliza novos materiais, processos, tecnologias, novas estratégias ou atividades; proporciona alteração de crenças por parte dos intervenientes. De outra forma, Hernandez et al (2000), nos fornecem indícios para conceituar inovação na prática educacional, a partir dos professores, da gestão escolar e de seus múltiplos atores e a concebe como respostas criativas e colaborativas às questões específicas de cada contexto educativo.

Nessa perspectiva, a inovação está estritamente atrelada à qualidade social da educação formal. De certo, não são conceitos e nem processos simples de serem adotados e implementados, e implicam, conforme dito acima, em múltiplas dimensões interligadas. É possível extrair dos marcos regulatórios das políticas educacionais para a EaD concepções de qualidade e de inovação? 


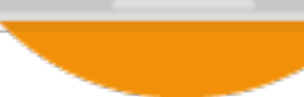

\subsection{Percursos metodológicos e achados prévios}

A pesquisa de abordagem qualitativa foi desenvolvida a partir de três procedimentos: i) estudo de referencial teórico sobre qualidade e inovação na educação; ii) levantamento dos marcos regulatórios da EaD no Brasil para constituição do corpus documental e iii) análise do corpus documental (em andamento). Nessa comunicação, apresentaremos resultados prévios, conforme já assinalado. Encontra-se abaixo quadro com o corpus documental constituído; bem como a ementa do texto legal.

Quadro 1- Principais Marcos Regulatórios da EaD (2005-2019)

\begin{tabular}{|c|c|c|c|c|}
\hline Número & Tipo & Ano & Ementa & Revoga \\
\hline 5.622 & Decreto & 2005 & $\begin{array}{l}\text { Regulamenta o art. } \underline{80} \text { da Lei no } \underline{9.394} \text {, de } 20 \text { de dezembro } \\
\text { de } 1996 \text {, que estabelece as diretrizes e bases da educação } \\
\text { nacional. }\end{array}$ & $\begin{array}{c}\text { Nenhuma } \\
\text { norma anterior }\end{array}$ \\
\hline 5.773 & Decreto & 2006 & $\begin{array}{l}\text { Dispõe sobre o exercício das funções de regulação, } \\
\text { supervisão e avaliação de instituições de educação superior } \\
\text { e cursos superiores de graduação e seqüenciais no sistema } \\
\text { federal de ensino. }\end{array}$ & $\begin{array}{c}\text { Nenhuma norma } \\
\text { anterior }\end{array}$ \\
\hline 6.303 & Decreto & 2007 & $\begin{array}{l}\text { Altera dispositivos dos Decretos n. }{ }^{\circ} 5.622 \text {, de } 19 \text { de } \\
\text { dezembro de } 2005 \text {, que estabelece as diretrizes e bases da } \\
\text { educação nacional, e } 5.773 \text {, de } 9 \text { de maio de } 2006 \text {, que } \\
\text { dispõe sobre o exercício das funções de regulação, } \\
\text { supervisão e avaliação de instituições de educação superior } \\
\text { e cursos superiores de graduação e seqüenciais no sistema } \\
\text { federal de ensino. }\end{array}$ & $\begin{array}{c}\text { Nenhuma } \\
\text { norma anterior }\end{array}$ \\
\hline 12.056 & Lei & 2009 & $\begin{array}{l}\text { Acrescenta parágrafos ao art. } 62 \text { da Lei } \mathrm{n}^{\circ} 9.394 \text {, de } 20 \text { de } \\
\text { dezembro de } 1996 \text {, que estabelece as diretrizes e bases da } \\
\text { educação nacional. }\end{array}$ & $\begin{array}{c}\text { Nenhuma resolução } \\
\text { anterior }\end{array}$ \\
\hline 564 & $\begin{array}{c}\text { Parecer } \\
\text { CNE/CES }\end{array}$ & 2015 & $\begin{array}{l}\text { Estabelece Diretrizes e normas nacionais para a oferta de } \\
\text { programas e cursos de educação superior na modalidade a } \\
\text { distância. }\end{array}$ & $\begin{array}{c}\text { Nenhuma } \\
\text { norma anterior }\end{array}$ \\
\hline 01 & $\begin{array}{l}\text { Resolução } \\
\text { CNE/ CES }\end{array}$ & 2016 & $\begin{array}{l}\text { Estabelece Diretrizes e Normas Nacionais para a Oferta de } \\
\text { Programas e Cursos de Educação Superior na Modalidade } \\
\text { a Distância. }\end{array}$ & $\begin{array}{c}\text { Nenhuma } \\
\text { norma anterior }\end{array}$ \\
\hline
\end{tabular}




\begin{tabular}{|c|c|c|c|c|}
\hline & & & $\begin{array}{l}\text { Fomento à Implementação de Escolas de Ensino Médio em } \\
\text { Tempo Integral. }\end{array}$ & \\
\hline 275 & $\begin{array}{l}\text { Portaria } \\
\text { Capes }\end{array}$ & 2018 & $\begin{array}{l}\text { Dispõe sobre os programas de pós-graduação stricto sensu } \\
\text { na modalidade a distância. }\end{array}$ & $\begin{array}{c}\text { Nenhuma } \\
\text { norma anterior }\end{array}$ \\
\hline 1.428 & $\begin{array}{l}\text { Portaria } \\
\text { MEC }\end{array}$ & 2018 & $\begin{array}{l}\text { Dispõe sobre a oferta, por Instituições de Educação } \\
\text { Superior - IES, de disciplinas na modalidade a distância em } \\
\text { cursos de graduação presencial. }\end{array}$ & $\begin{array}{l}\text { Portaria MEC } \mathrm{n}^{\mathrm{o}} \\
1.134, \text { de } 10 \mathrm{de} \\
\text { outubro de } 2016\end{array}$ \\
\hline 90 & $\begin{array}{l}\text { Portaria } \\
\text { Capes }\end{array}$ & 2019 & $\begin{array}{l}\text { Dispõe sobre os programas de pós-graduação stricto sensu } \\
\text { na modalidade de educação a distância }\end{array}$ & $\begin{array}{l}\text { Portaria Capes } n^{\circ} \\
275 \text {, de } 18 \text { de } \\
\text { dezembro de } 2018\end{array}$ \\
\hline 2.117 & $\begin{array}{l}\text { Portaria } \\
\text { MEC }\end{array}$ & 2019 & $\begin{array}{l}\text { Dispõe sobre a oferta de carga horária na modalidade de } \\
\text { Ensino a Distância - EaD em cursos de graduação } \\
\text { presenciais ofertados por Instituições de Educação Superior } \\
\text { - IES pertencentes ao Sistema Federal de Ensino. }\end{array}$ & $\begin{array}{l}\text { Portaria MEC n } \\
1.428, \text { de } 28 \text { de } \\
\text { dezembro de } 2018\end{array}$ \\
\hline
\end{tabular}

Fonte: elaboração dos autores, 2020

Dos quatorze institutos legais elencados no quadro acima, de 2005 a 2019, observa-se uma predominância de atos administrativos do executivo, em instâncias diferenciadas, para regular a matéria da EaD. São 5 decretos do executivo cujos teores versam, em linhas gerais, sobre a regulamentação do artigo 80 da Lei de Diretrizes e Bases da Educação Nacional de 1996 e sobre o exercício das funções de regulação, supervisão e avaliação de instituições de educação superior. 6 portarias normativas, sendo 2 oriundas da Coordenação de Aperfeiçoamento de Pessoal de Nível Superior (CAPES), quando se refere a ato administrativo de efeito concreto, relativo à pós-graduação e 4 portarias oriundas do Ministério da Educação (MEC), referentes à normas para o credenciamento de instituições e a oferta de cursos superiores a distância e para a oferta de carga horária em EaD em instituições presenciais. 1 parecer da Câmara de Educação Superior do Conselho Nacional de Educação e 1 Resolução da mesma Câmara e órgão supracitado. O parecer se configura como um estudo técnico sobre 


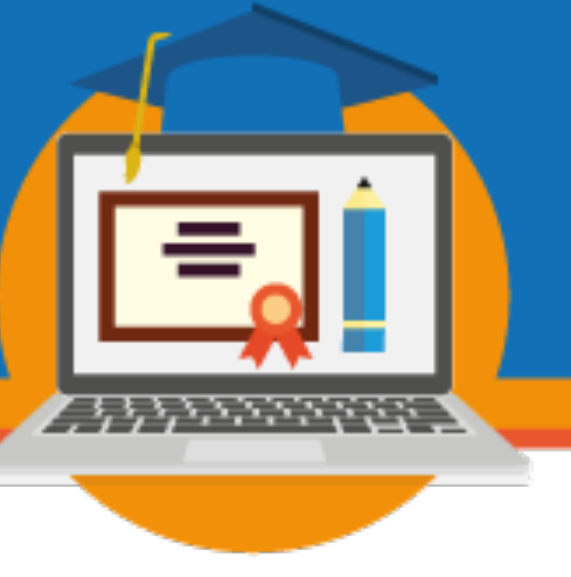

determinado tema, auxilia e subsidia tomadas de decisão e, no caso em tela, auxiliou a elaboração da Resolução $\mathrm{n}^{\circ} 01$ de 2016.

Selecionaram-se as peças legais desde 2005 até 2019, atravessando diferentes conjunturas políticas, a fim de perceber permanências e descontinuidades, no que tange à oferta da educação superior a distância de forma geral e, de forma específica, no que tange às concepções de qualidade e inovação. Muito embora, o quadro acima apresente o corpus documental constituído, tratando em amplo espectro desde regulação, supervisão e avaliação em cursos a distância, oferta de disciplinas na modalidade a distância em Instituições de Educação Superior presenciais, passando pela reforma do Ensino Médio até sobre a disposição de programas de Pós-Graduação stricto sensu; para efeitos desta exposição, a análise recaiu nos marcos regulatórios, de 2016 e 2017, que tratam dos cursos de graduação, a saber: Resolução n ${ }^{\circ}$ 1/ 2016 CNE/CSE, Decretos ns 9235 e 9057 de 2017 e Portaria 11 do MEC de 2017.

\subsection{Qualidade e Inovação nos marcos regulatórios da EaD}

As normas jurídicas selecionadas para análise, no espaço deste estudo, referem-se a duas conjunturas políticas distintas. A Resolução $n^{\circ}$ 1/2016 do CNE/CSE entrou em vigor em março de 2016, e objetivou estabelecer Diretrizes e Normas Nacionais para a Oferta de Programas e Cursos de Educação Superior na Modalidade a Distância. Tais Diretrizes se configuraram como base para as políticas de avaliação e de regulação dos cursos a distância das IES. Além do que, a Resolução consolidou os fundamentos teóricos estabelecidos no Parecer 564/2015. A Comissão designada para elaborar o Parecer 564/2015 discutiu o tema com diferentes setores da sociedade civil organizada, além de promover seminários e audiências públicas, versando sobre a oferta da educação superior na modalidade a distância. O eixo estruturante do Parecer girava em torno da garantia da qualidade dos cursos oferecidos na Modalidade a distância (BRASIL, CNE, 2015).

A partir dessas considerações iniciais, extraem-se da Resolução, três aspectos para 


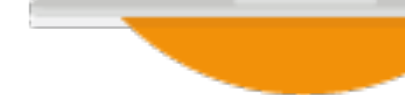

Ao passo que, no ano de 2017, de maio a dezembro, um conjunto de marcos regulatórios para a educação a distância entrou em vigor, o Decreto $\mathrm{n}^{\circ} 9.057$, de 25 de maio, a Portaria normativa $\mathrm{n}^{\circ} 11$, de 29 de junho e o Decreto $\mathrm{n}^{\circ}$ 9.235, de 15 de dezembro. Estabeleceu-se uma tríade de instrumentos legais que caminharam em direção às reivindicações do mercado educacional e dos grupos que, ao longo da história dos marcos legais para a $\mathrm{EaD}$, defenderam maior desregulamentação do Estado e maior liberdade para que as leis do mercado, pautadas na competitividade da oferta, pudessem definir a qualidade dos cursos (LACÉ, 2014).

Respectivamente, as normas descritas acima referem-se à regulamentação do artigo 80 da LBD/1996, dispondo sobre a oferta da educação básica e superior na modalidade a distância; as normas de credenciamento de instituições e oferta de cursos superiores a distância; e sobre o exercício das funções de regulação, supervisão e avaliação das IES.

Em linhas gerais, da atualização dos marcos regulatórios para a $\mathrm{EaD}, 5$ elementos foram retirados para análise. i) conceito mais enxuto da modalidade a distância, em comparação à Resolução $n^{\circ} 1 / 2016$, pois a proposição de maior articulação e efetiva complementaridade entre a presencialidade e a virtualidade; bem como a consideração com a participação democrática nos processos de ensino e aprendizagem de estudantes e profissionais da educação (professores, tutores e gestores) foram retiradas do Caput do Art. $1^{\circ}$, do Decreto 9.057/2017. ii) As IES credenciadas para a oferta de cursos superiores a distância poderão criar Pólos de apoio presencial por ato próprio, considerando como barreira, para o quantitativo máximo de Pólos, o Conceito Institucional (CI) mais recente da instituição.

O CI faz parte das dimensões avaliativas do Sistema Nacional de Avaliação da Educação Superior (SINAES), e é constituído a partir da avaliação in loco que considera dentre outros aspectos, o PDI, as políticas de gestão, ensino, pesquisa e extensão. Segundo o Art. 12 da Portaria Normativa $\mathrm{n}^{\mathrm{o}} 11$, de 2017, as IES com CI 3, poderão criar anualmente 50 Pólos, as IES com conceito 4 poderão criar anualmente 150 Polos e as IES com conceito 5 poderão criar por ato próprio até 250 Pólos (BRASIL, 2017).

III) A avaliação in loco será realizada na Sede institucional excluindo a avaliação in loco nos Pólos de apoio presencial. A verificação da existência de adequação de metodologias, 
infraestrutura física, tecnológica e de pessoal para os Polos será feita, por meio de documentos ou por meio da utilização de recursos tecnológicos disponibilizados pelas IES, no momento da visita avaliativa na sede institucional. (BRASIL, 2017). IV) As instituições credenciadas para oferecer cursos de graduação a distância podem oferecer cursos de pós-graduação lato sensu, sem necessidade de credenciamento distintos. E por fim; v) é permitido o credenciamento de instituições de ensino superior exclusivamente para a oferta de cursos de graduação e pósgraduação na modalidade a distância.

Para a Associação Brasileira de Mantenedores do Ensino Superior (ABMES, 2018), a atualização da legislação da $\mathrm{EaD}$ no Brasil, significou uma grande revolução na educação superior brasileira por desburocratizar o sistema e abrir espaço para que o monitoramento seja feito pelos próprios alunos, pelo mercado e pela concorrência. A qualidade dos cursos EaD, nessa percepção, será regulada pelas relações mercantis e pela competitividade.

Tendo em vista, o incentivo para o uso da modalidade a distância, do ponto de vista das atuais políticas públicas para a educação superior e o breve retrato dos marcos regulatórios da EaD, Alonso (2009), Dourado (2011) e Lima (2014) evidenciam que, entre as problemáticas que envolvem a modalidade a distância, é possível indicar alguns elementos que dificultam a qualidade dos cursos. Destacam-se: a expansão da EaD na educação superior desenvolveu um mercado educacional na oferta desses cursos e um processo de precarização do trabalho docente por conta da estrutura de trabalho, inclusive as formas de contratação, seja nas Instituições de Ensino (IES) privadas, seja nas públicas; a lógica expansionista está baseada numa perspectiva quantitativa e privatista; a materialização dos cursos sem as mínimas condições das políticas e propostas para a modalidade; tendência de definição de um modelo de EaD para o Brasil e modelo de fomento dos cursos para as IES públicas baseada em atendimento à editais, de forma individualizada e não como uma ação institucional.

Importa considerar ainda que, em relação ao arcabouço legal da EaD, Lima e Assis (2018), destacam que a modalidade tem sido utilizada como estratégia para a expansão da educação superior, principalmente pela esfera privada e que, nos três últimos anos tem ocorrido um (des) caminho do atual governo Jair Messias Bolsonaro e do governo de Michel Miguel

\section{SEMINÁRIO DE EDUCAÇÃO A DISTÂNCIA}

Diálogos sobre EaD e uso das TDIC na educação: regulamentação em tempos recentes 3 a 6 de novembro de 2020 - Brasília/DF - Online 


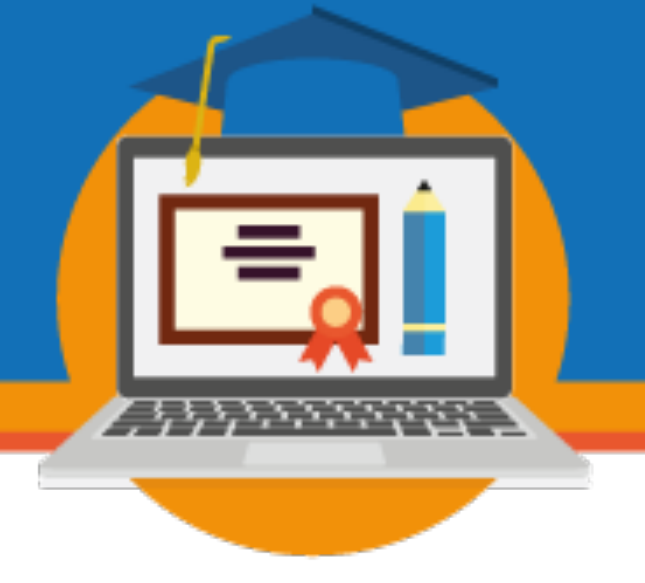

Elias Temer Lulia, por meio das mudanças em quase todas as regulamentações da EaD.

Demonstra-se, com essas mudanças, tendência neoliberal para ampliação do mercado, tornando a oferta da EaD mais flexível e não como forma democrática de acesso e inclusão com qualidade socialmente referenciada.

\section{Considerações Finais}

O objetivo deste trabalho foi apresentar alguns resultados prévios da pesquisa "Política de expansão da educação a distância na UnB: qualidade e inovação em questão" vinculada ao Programa Institucional de Iniciação Científica (PIBIC). Partiu-se de um dos objetivos específicos estipulados no estudo que previa a análise das concepções de qualidade e inovação expressas nas regulamentações da EaD no Brasil (2016-2017). Evidenciou-se, por meio, da abordagem qualitativa e da análise em fontes primárias e secundárias que, a atualização dos marcos regulatórios para a $\mathrm{EaD}$, em 2017, atendeu parte das reivindicações do mercado educacional que, ao longo da história do marcos legais da EaD, no Brasil, reivindicou maior desregulamentação do Estado e desburocratização por parte do Ministério da Educação. De acordo, com essa concepção, a qualidade será autorregulada pelo mercado, pela concorrência, pela competitividade e pela avaliação dos "clientes".

O conceito de inovação não foi identificado de forma direta, nos marcos regulatórios estudados, todavia, foi possível elencar algumas problematizações: o que pode significar inovação, nesse cenário de incentivo da oferta da EaD nos cursos de graduação e pós-graduação 


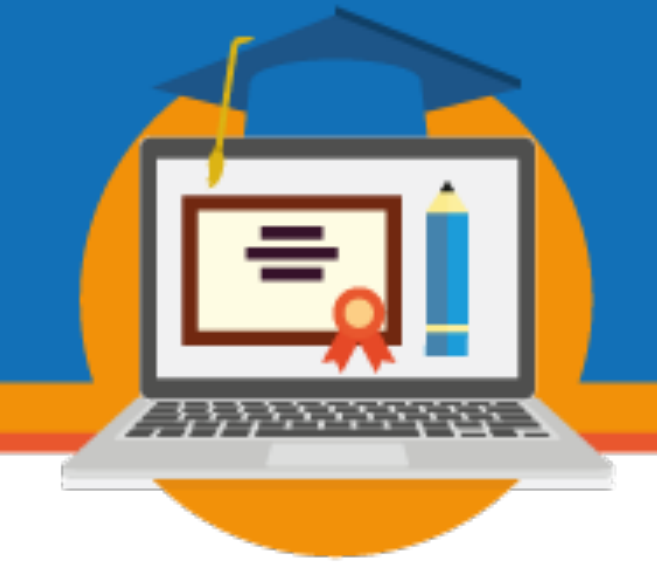

lato e stricto sensu? Será que, os PDIs, PPIs e PPCs, das IES credenciadas no novo marco legal, expressam conceitos de inovação? Quais seriam? E quais elementos caracterizam a inovação, nessa conjuntura atual estilhaçada pela pós-verdade, pelo individualismo e pela busca desenfreada pelo lucro?

\section{Referências}

ALONSO, Kátia Morosov. Educação a distância e tutoria: anotações sobre o trabalho docente. In: ALONSO, Kátia Morosov; RODRIGUES, Rosangela Schawarz; BARBOSA, Joaquim Gonçalves (Orgs.). Educação a distância - práticas, reflexões e cenários plurais. Cuiabá, MT: Central de Texto: EdUFMT, 2009. P. 81-98.

BRASIL. Plano de desenvolvimento da educação: razões, princípios e programas, Brasília, DF, 2007. Disponível em:<http://portal.mec.gov.br/arquivos/livro/livro.pdf>. Acesso em: 14 abr. 2019.

Decreto 5.622, de 19 de dezembro de 2005, disponivel

em:<http://www.planalto.gov.br/ccivil_03/_Ato2004-2006/2005/Decreto/D5622.htm>. Acesso em: 16 fev. 2020.

Decreto 5.773, de 9 de maio de 2006, disponivel em:<http://www.planalto.gov.br/ccivil_03/_Ato2004-2006/2006/Decreto/D5773.htm> Acesso em: 16 fev. 2020.

. Decreto 5.800 de 2006. Disponível em: <http://www.planalto.gov.br/ccivil_03/_Ato20042006/2006/Decreto/D5800.htm>. Acesso em: 14 abr. 2019.

Decreto 6.303, de 12 de dezembro de 2007, disponível em:<http://www.planalto.gov.br/ccivil_03/_Ato2007-2010/2007/Decreto/D6303.htm > Acesso em: 16 fev. 2020. 


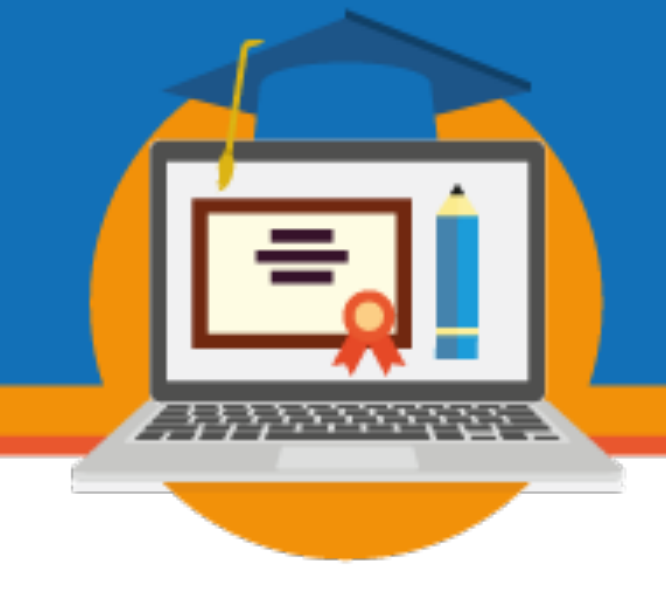

Decreto 9.057, de 25 de maio de 2017, disponível

em:<http://www.planalto.gov.br/ccivil_03/_Ato2015-2018/2017/Decreto/D9057.htm> Acesso em: 16 fev. 2020.

Decreto 9.235, de 15 de de dezembro de 2017, disponível

em: $<$ http://www.planalto.gov.br/ccivil 03/ Ato2015-2018/2017/Decreto/D9235.htm $>$ Acesso em: 16 de fevereiro de 2020.

Lei 12.056, de 13 de outubro de 2009, disponível em:<http://www.planalto.gov.br/ccivil_03/_Ato2007-2010/2009/Lei/L12056.htm> Acesso em: 16 de fevereiro de 2020.

Lei 13.415, de 16 de fevereiro de 2017, disponível

em:<http://www.planalto.gov.br/ccivil 03/ Ato2015-2018/2017/Lei/L13415.htm> Acesso em:

16 fev. 2020.

. Plano Nacional de Educação (2001-2010). Disponível em:

http://portal.inep.gov.br/documents/186968/484184/Plano+Nacional+de+Educa\%C3\%A7\%C3\%A3o+ $\% 28$ PNE \%29++Quest\%C3\%B5es+Desafiadoras+e+Embates+Emblem\%C3\%A1ticos/83bf0759-5c9e4862-b719-81bb6cc3f9e3?version=1.2. Acesso em: 14 abr. 2019.

Portaria 1.428, de 28 de dezembro de 2018, disponível

em: $<$ http://portal.mec.gov.br/index.php?option=com_docman\&view=download\&alias=108231portaria-1428\&category_slug=fevereiro-2019-pdf\&Itemid=30192 >. Acesso em: 16 fev. 2020.

Portaria 2.117 de 6 de dezembro de 2019, disponível em:<http://www.in.gov.br/en/web/dou//portaria-n-2.117-de-6-de-dezembro-de-2019-232670913>. Acesso em: 16 fev. 2020.

Portaria Normativa, 11 de 20 de junho de 2017, disponível

em:<http://portal.mec.gov.br/index.php?option=com_docman\&view=download\&alias=66441-

pn-n11-2017-regulamentacao-ead-republicada-pdf\&category_slug=junho-2017-pdf\&Itemid=30192> . Acesso em: 16 fev. 2020

DOURADO, L. F.; OLIVEIRA, J. F. de. A qualidade da educação: perspectivas e desafios. Cadernos Cedes. Campinas: Unicamp, v. 29, n. 78, 2009, p. 201-215.

HERNÁNDEZ, Fernando et al. Aprendendo com as inovações na escola. Porto Alegre: Edições Artes Médicas Sul, 2000.

LACÉ, Andréia Mello. A Universidade aberta do Brasil: das origens na ditadura militar ao século XXI. Tese. Brasília: Faculdade de Educação, Universidade de Brasília, 2014.

III SEMINÁRIO DE EDUCAÇÃO A DISTÂNCIA

Diálogos sobre EaD e uso das TDIC na educação: regulamentação em tempos recentes 3 a 6 de novembro de 2020 - Brasília/DF - Online 


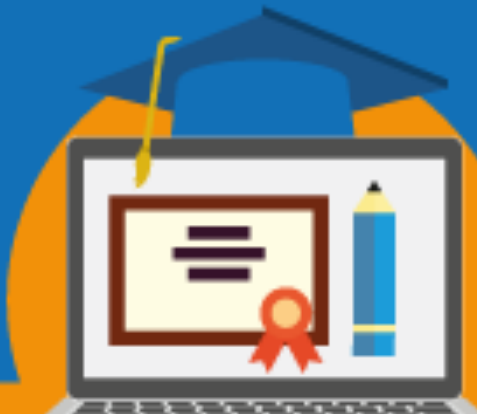

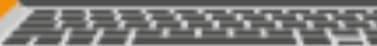
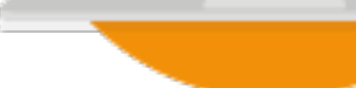

LIMA, Daniela da Costa Britto Pereira Lima. Documento técnico contendo estudo analítico das diretrizes, regulamentações, padrões de qualidade/regulação da EAD, com vistas a identificar políticas e indicadores de expansão da Educação Superior em EAD. Produto 1, Conselho Nacional de Educação/UNESCO, 2014.

Panorama da EaD no Brasil e na região Centro-Oeste. Relatório Técnico da pesquisa A Institucionalização da Educação Superior a Distância nas Universidades Federais da Região CentroOeste: Processos, Organização e Práticas. Acta Qualidade, Tecnologias e Educação a Distância, v. 1, n. 6, 2018, p. 24-46.

LIMA, D. C. B. P. ; ASSIS, L. M. de. Arena constitutiva da Educação Superior a Distancia: as regras do jogo e como o jogo é jogado. Revista Brasileira de Política e Administração da Educação, v. 34, n. 1, 2018. Disponível em: <http://seer.ufrgs.br/index.php/rbpae/article/view/82461/48069>. Acesso em: 14 abril 2019.

SILVA, Maria Abádia da. Qualidade social da educação pública: algumas aproximações. Cad. Cedes, vol. 19, n. 78, p. 216-226. Disponível em: http://www.cedes.unicamp.br. Acesso em: 15 fev. 2020.

OLIVEIRA, I.; COURELA, C. Mudança e inovação em educação: o compromisso dos professores. Interacções, n. 27, 2013, p. 97-117. Disponível em: <

https://revistas.rcaap.pt/interaccoes/article/view/3404>. Acesso em: 14 abril 2019. 